\title{
The effect of repeat consumption on the perceived taste and liking of oral nutritional supplements
}

\author{
L. Methven ${ }^{1}$, O. B. Kennedy ${ }^{1}$, D. S. Mottram ${ }^{1}$, K. Rahelu ${ }^{1}$, N. Economou ${ }^{1}$ and M. A. Gosney ${ }^{2}$ \\ ${ }^{1}$ Department of Food Biosciences and ${ }^{2}$ Institute of Health Sciences, University of Reading, Reading RG6 6AP, UK
}

The compliance of oral nutritional supplements (ONS) is often poor. Wastage of ONS can be as high as $60 \%$; with highest levels found in patients reporting taste dislikes $(73 \%)^{(1)}$. Sensory testing of products is typically performed on small consumption volumes (often 5-20 ml). However, target consumption volume for patients is typically $200 \mathrm{ml}$ two to three times daily. The present study aimed to evaluate sensory characteristics and liking of ONS following consumption of approximately one-third of the $200 \mathrm{ml}$ pack volume.

A commercial vanilla ONS product was tested. A trained sensory panel ( $n$ 12, age range 33-59 years) carried out a sequential profile: tasting eight consecutive $5 \mathrm{ml}$ aliquots of ONS; scoring five attributes at each tasting; re-scoring as after effects at $30 \mathrm{~s}$ and $60 \mathrm{~s}$ post tasting. A healthy older volunteer panel ( $n$ 32; age range 62-88 years) tasted two types of vanilla ONS: standard commercial product; a product in which sweetness had been reduced by the addition of a sweetness suppressor sodium 2-(4-methoxyphenoxy)-propanoate (lactisole; $0.003 \mathrm{~g} / 100 \mathrm{ml}$ ). Initial liking and final liking were scored following a boredom test ${ }^{(2)}$. Volunteers tasted each sample $(5 \mathrm{ml})$ and scored their liking for each on a nine-point hedonic scale. Subsequently, they tasted a series of eight consecutive $5 \mathrm{ml}$ aliquots of one of the samples before scoring their final liking for each sample. All presentation orders were balanced, total consumption volume $60 \mathrm{ml}$.

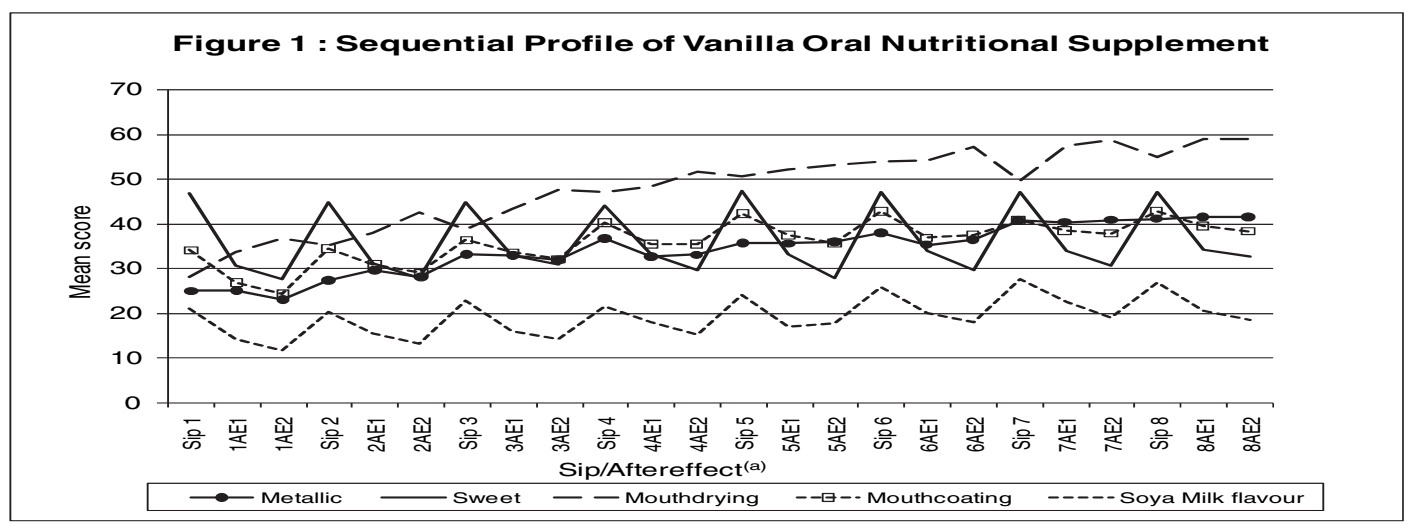

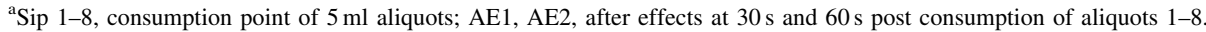

Data from the trained panel demonstrateda significant build up of mouth drying, metallic, mouth coating and soya-milk flavour $(P<0.0001)$ over repeat consumption, whereas sweetness did not build up. Mean liking scores from the older volunteers for the standard commercial vanilla product decreased significantly $(P<0.0001)$ from 6.3 to 5.0 following $60 \mathrm{ml}$ consumption. The liking of ONS decreased when consumption was increased from $10 \mathrm{ml}$ to $60 \mathrm{ml}$. The decrease in liking may be a result of the sensory attributes that were found to increase with repeat consumption. To improve the compliance of ONS the negative sensory attributes that increase over consumption time must be reduced.

1. Gosney M (2003) $J$ Adv Nursing 43, 275-280.

2. Köster EP \& Mojet J (2007) In Consumer-led Food Product Development, pp. 262-280 [H MacFie, editor]. Cambridge: Woodhead Publishing Limited. 